\title{
Generalization of the Annuity Factor
}

\author{
Joerg Wilde ${ }^{1}$ \\ ${ }^{1}$ Pension Fund of Water Associations (Ruhrverband), Essen, Germany \\ Correspondence: Joerg Wilde, Ruhrverband, 45128 Essen, Kronprinzenstr, 37, Germany.
}

Received: January 10, 2018

Accepted: January 29, 2018

Online Published: February 6, 2018

doi:10.5430/afr.v7n2p83

URL: https://doi.org/10.5430/afr.v7n2p83

\begin{abstract}
The well-known Annuity Factor, restricted to constant payments only, can be generalized for time dependent payments. A Generalized Annuity Factor (GAF) broadens the application potential considerably as is shown exemplarily for the valuation of loans and pension obligations. For the first time for such linear and nonlinear payments over time, compressed closed-form formulae for important financial key numbers such as present value, duration, convexity or value at risk can be derived. Moreover, easy computation makes General Annuity Factors a useful valuation tool especially in the field of finance and accounting. As General Annuity Factors can be implemented as User Defined Functions in a spreadsheet program, calculations can also be done in smaller firms or public services. Because of its computational efficiency the new instrument is also suitable for far-sighted economical models such as Asset Liability Management models (ALM) or life-cycle valuation models concerning products, investments or stocks.
\end{abstract}

Keywords: General annuity factor, Present value, Value at risk, Loans, Pension obligations, Life cycle

\section{JEL Classification: C02, G12, G17, L11, M41}

\section{Introduction and Literature Review}

The Annuity Factor is routinely used in many economical fields to calculate the present value of an annuity which is a cash flow stream with a limited number of periodic payments of the same amount. The annuity factor concept allows an easy computation of the present value as a simple product of the constant payment amount and the Annuity Factor. Annuity Factor tables for different discount rates and number of periods are found in the back of most finance textbooks and online. In addition, Annuity Factors are provided by financial calculators and are also implemented as financial functions in spreadsheet programs. As documented by Rubinstein (2003) in his series of articles "Great Moments in Financial Economics", a closed-form algebraic solution for the present value $P V$ of an annual annuity with a constant payment of $c$ for $n$ consecutive years in respect to a discount rate $i$ can be traced back more than 250 years.

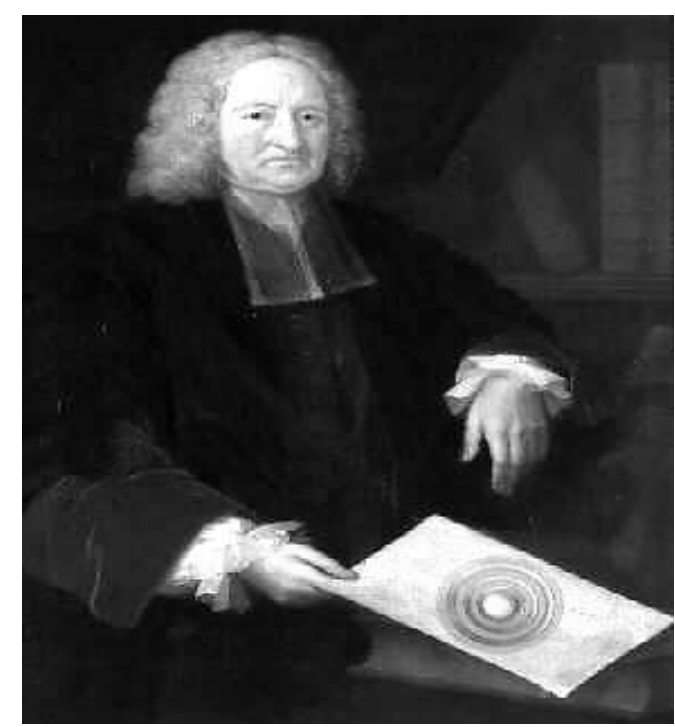

Figure 1. Edmond Halley (1656 -1742) 
In 1761 the well-known formula

$$
P V=c\left[1-(1+i)^{-n}\right] / i \text { with } i \neq 0
$$

which has been derived by Edmond Halley (1761), better known for the comet bearing his name, was published posthumously. In (1) the term $\left[1-(1+i)^{-n}\right] / i$ is the Annuity Factor. In the notation used further on, this factor is denoted as $\boldsymbol{a}(\boldsymbol{0} ; \boldsymbol{n} ; \boldsymbol{i})$ as it is determined by the number of consecutive payment periods $n$ from the date of valuation $t=0$ and by the given discount rate $i$.

Not surprisingly, due to the computational efficiency, there is a great variety of application literature. Representatively, we refer to Lyuu (2002). Some extensions to Halley's Annuity Factor should be mentioned.

With only a slight modification a special case of growing annuity can be incorporated. This is the case when each payment grows by a constant growth factor over a limited number of periods, starting from the annuity payment in the first period. As we will see later on in section 2.1, the growth factor can be combined with the discounting factor into a new modified discounting factor. A well-known application is the valuation of stocks by the Dividend Growth Model assuming a constant dividend growth factor (Gordon, 1962). When the number of periods goes to infinity, the Annuity Factor shrinks to the reciprocal of the difference between discount and growth rate. In a recently published paper Holland (2018) develops closed-form expressions for multi-stage versions of the Dividend Growth Model with different growth rates and declining growth rates. In spite of the extension for constant growth the Annuity Factor Concept is based on a constant payment schedule. Often this does not match reality.

In the course of takeovers of municipal waste water networks in the early 2000s in Germany the author was faced with the valuation of up to one hundred thousand assets generating future payments following an exactly linear time dependency (caused by loan payments) and an approximately U-shaped (quadratic) time dependency (caused by maintenance expenses) during their long-lasting life time. The traditional method of calculating, discounting and finally summation of each future payment for time index $t=1, \ldots, n$ would have caused massive computational problems because of too many valuation objects and valuation periods. Thus there was an urgent need for an easy-to-handle closed-form "timeless" valuation tool like Halley's formula. The suitable new tool, the General Annuity Factor (GAF), was developed until 2005 (and immediately applied) including the proof that Halley's formula is the zero-case of the GAF valuation formula for arbitrary degrees $m=0,1,2, \ldots$ of time dependency, e.g. $\mathrm{m}=1$ for a linear, $\mathrm{m}=2$ for a quadratic time dependency (Wilde, 2005). A later paper of Wilde, Oelmann, and Römmich (2015) focused on a maturity adjusted valuation of infrastructure networks using GAF. In a recently published paper of Wilde (2018) GAF-valuation of strategies like centralization, standardization and life-extending maintenance of network assets is in the focus of a far-sighted Asset Controlling. Especially accounting is a very important field of application for the new tool: GAF provide an efficient, time exact and even maturity adjusted valuation of pension obligations for balance requirements and, beyond, an anticipatory controlling of their cash and return effects (Wilde, 2016).

This paper is divided into four sections. After introduction in the second section at first the mathematical foundation of the GAF and its easy computation by a recursive scheme starting with Halley's Annuity Factor is shown. Then for arbitrary time dependent processes of different time degrees which are combined into a polynomial function, easy valuation is demonstrated just by substituting the time powers in the polynomial function by the according GAF. Finally in this section, beyond present value, general closed-form expressions for duration, convexity and value at risk for time dependent cash flows are derived. The third section illustrates the broad applicability of the new tool exemplarily for loans, product life cycles and pension obligations. A universal valuation scheme is provided for spreadsheet programs implementing GAF as User Defined Functions. Finally in the fourth section, after summarizing the most important features of GAF further application potentials of GAF as well as further directions of research on this subject are discussed.

\section{Generalization of the Annuity Factor Concept}

\subsection{Halley's Annuity Factor}

Using the according discount factor $q=1+i$ instead of the discount rate $I$, Halley's Annuity Factor can be alternatively stated as

$$
\boldsymbol{a}(\boldsymbol{0} ; \boldsymbol{n} ; \boldsymbol{q})=\left[1-q^{-n}\right] /(q-1) \text { with } \mathrm{q} \neq 1 .
$$

The Annuity Factor can be interpreted as the present value of constant payments of a unity, e.g. $\$ 1$. It is the closed-form expression of an $n$-sum of discounting factors $\Sigma q^{-t}$. Thus it avoids discounting of each single payment 
and subsequent summation along the time index $t=1, \ldots, n$. In this respect it is "timeless". In the following we consider so called ordinary annuities (payment at the end of the time period). Annuities due (payment at the beginning of the time period) can easily be obtained multiplying ordinary annuities by $q$. As mentioned before, unfortunately, application of the Annuity Factor Concept is restricted to constant payments, formally to constant payment processes $C F(t)=c(t=1, \ldots, n)$, only.

\subsection{Derivation of the General Annuity Factor and Recursive Computation}

If it is possible to expand the above simple rule generally to time dependent payment processes, this would broaden the application potential of the Annuity Factor Concept considerably. Not only payments constant over time, but also linear $\left(t^{l}\right)$ and nonlinear $\left(t^{m}, m=2,3, \ldots\right)$ over time varying payments could easily be valued then. For any time dependent payment process $C F(t)$ of degree $m=0,1,2, \ldots$ such as

$$
C F(t)=c_{m} t^{m}(t=1, \ldots, n)
$$

where $c_{m}$ is a specified payment coefficient (specified annuity) for degree $m$ of the time dependency, the present value $P V$ could be then computed as a simple product of specified annuity $c_{m}$ and a closed-form Annuity Factor $\boldsymbol{a}_{\boldsymbol{m}}(\boldsymbol{0} ; \boldsymbol{n} ; \boldsymbol{q})$ of degree $m$

$$
P V=c_{m} \boldsymbol{a}_{\boldsymbol{m}}(\mathbf{0} ; \boldsymbol{n} ; \boldsymbol{q}) .
$$

As proved by Wilde (2005) and shown in the Appendix the present value of $n$ consecutive payments of a $t^{m}$-multiple of a payment unity, with $m=0,1,2, \ldots$ being an arbitrary degree of time dependency, is obtained for a given discount rate $i$ or discount factor $q$ by the General Annuity Factor (GAF)

$$
\boldsymbol{a}_{\boldsymbol{m}}(\mathbf{0} ; \boldsymbol{n} ; \boldsymbol{q})=\left[1-(n+1)^{m} q^{-n}+\sum^{-1}\left({ }^{m}{ }_{k}\right) \boldsymbol{a}_{k}(\boldsymbol{0} ; \boldsymbol{n} ; \boldsymbol{q})\right] /(q-1) \text { with } q \neq 1,
$$

which is the closed-form expression of a $n$-sum of discounted $m$-th time powers $\Sigma t^{m} q^{-t}$. GAF-Formula (5) includes formula (2) as a special case $\boldsymbol{a}_{\boldsymbol{0}}(\mathbf{0} ; \boldsymbol{n} ; \boldsymbol{q})$ with a degree of $m=0$. The underlying constant payment process can according to the structure of (3) be written as $C F(t)=c_{0} t^{0}\left(t=1, \ldots, n\right.$ and $\left.t^{0}=1\right)$.

At first glance computation of GAF according to (5) seems to be laborious. Actually for any degree $m$ the according GAF can be easily computed in a recursive manner starting from Halley's Annuity Factor subject to (2) by the following bootstrap procedure

$$
\begin{gathered}
\boldsymbol{a}_{0}(\mathbf{0} ; \boldsymbol{n} ; \boldsymbol{q})=\left[1-q^{-n}\right] /(q-1) \\
\boldsymbol{a}_{1}(\mathbf{0} ; \boldsymbol{n} ; \boldsymbol{q})=\left[1-(n+1)^{1} q^{-n}+\boldsymbol{a}_{0}(\mathbf{0} ; \boldsymbol{n} ; \boldsymbol{q})\right] /(q-1) \\
\boldsymbol{a}_{2}(\mathbf{0} ; \boldsymbol{n} ; \boldsymbol{q})=\left[1-(n+1)^{2} q^{-n}+\boldsymbol{a}_{0}(\mathbf{0} ; \boldsymbol{n} ; \boldsymbol{q})+2 \boldsymbol{a}_{1}(\mathbf{0} ; \boldsymbol{n} ; \boldsymbol{q})\right] /(q-1) \\
\boldsymbol{a}_{3}(\mathbf{0} ; \boldsymbol{n} ; \boldsymbol{q})=\left[1-(n+1)^{3} q^{-n}+\boldsymbol{a}_{0}(\mathbf{0} ; \boldsymbol{n} ; \boldsymbol{q})+3 \boldsymbol{a}_{1}(\mathbf{0} ; \boldsymbol{n} ; \boldsymbol{q})+3 \boldsymbol{a}_{2}(\mathbf{0} ; \boldsymbol{n} ; \boldsymbol{q})\right] /(q-1) \\
\boldsymbol{a}_{4}(\mathbf{0} ; \boldsymbol{n} ; \boldsymbol{q})=\left[1-(n+1)^{4} q^{-n}+\boldsymbol{a}_{0}(\mathbf{0} ; \boldsymbol{n} ; \boldsymbol{q})+4 \boldsymbol{a}_{1}(\mathbf{0} ; \boldsymbol{n} ; \boldsymbol{q})+6 \boldsymbol{a}_{2}(\mathbf{0} ; \boldsymbol{n} ; \boldsymbol{q})+4 \boldsymbol{a}_{3}(\mathbf{0} ; \boldsymbol{n} ; \boldsymbol{q})\right] /(q-1)
\end{gathered}
$$

and so on using the general formula (5).

The numbers in front of the GAF on the right side of the equations are known as binomial coefficients $\left({ }^{m}{ }_{k}\right)$, $k=0, \ldots, m-1$. The recursive computation makes it easy to implement GAF as so called User Defined Functions in spreadsheet programs.

Regarding inflation, time dependent payment processes may have additional systematic growth tendencies. Such tendencies can easily be included in the GAF. Given an inflation or growth rate $p \%$, thus an inflation or a growth factor $p=1+p \%$, we obtain a modified discounting factor

$$
q^{*}=q / p .
$$

The inflation or growth factor $p$ lowers or even overcompensates the discounting effect. Replacing $q$ in (5) or in (5a-e) by this factor even inflation or growth affected payment processes can directly be valued by using GAF $a_{m}\left(0 ; n ; q^{*}\right)$. 


\subsection{Combinations of Time Dependent Processes}

Combining several time dependent processes as defined in (3) in a polynomial function up to a maximum degree of $m$ allows modelling even more complex time dependent payment processes (see for example Figures 3,5 or 6 ) such as

$$
C F(t)=c_{0} \boldsymbol{t}^{0}+c_{1} \boldsymbol{t}^{1}+c_{2} \boldsymbol{t}^{2}+\ldots+c_{m} \boldsymbol{t}^{m}=\sum_{k=0}^{m} c_{k} \boldsymbol{t}^{k} \quad(t=1, \ldots, n) .
$$

In order to show the identical structure of payment and valuation function we generally denote time powers as $t^{k}$ in correspondence to GAF $\boldsymbol{a}_{\boldsymbol{m}}(\mathbf{0} ; \boldsymbol{n} ; \boldsymbol{q})$, although formally this is not necessary for $k=0$ and $k=1$ because of $t^{0}=1$ and $t^{l}=t$. Using GAF $\boldsymbol{a}_{k}(\mathbf{0} ; \boldsymbol{n} ; \boldsymbol{q})$ for $k=0, \ldots, m$, the formula of the present value for such a complex payment process shows an identical structure

$$
\begin{aligned}
& \text { m } \\
& P V=c_{0} \boldsymbol{a}_{0}(\mathbf{0} ; \boldsymbol{n} ; \boldsymbol{q})+c_{1} \boldsymbol{a}_{\mathbf{l}}(\mathbf{0} ; \boldsymbol{n} ; \boldsymbol{q})+c_{2} \boldsymbol{a}_{2}(\mathbf{0} ; \boldsymbol{n} ; \boldsymbol{q})+\ldots+c_{m} \boldsymbol{a}_{\boldsymbol{m}}(\mathbf{0} ; \boldsymbol{n} ; \boldsymbol{q})=\sum c_{k} \boldsymbol{a}_{k}(\mathbf{0} ; \boldsymbol{n} ; \boldsymbol{q}) . \\
& k=0
\end{aligned}
$$

In practice, time dependent payment processes can be modelled in most cases by time polynomials of a maximum degree of no more than $m=4$. Equation (8) holds valid for the inflation including GAF $\boldsymbol{a}_{\boldsymbol{k}}\left(\boldsymbol{O} ; \boldsymbol{n} ; \boldsymbol{q}^{*}\right)$ as well.

\subsection{Arbitrary Valuation in Time}

Regarding practise, valuation at the beginning of a payment process $(t=0)$ may not be appropriate. Often a certain number $x$ of time periods is already expired. Thus the task is to value the residual payment process lasting $n-x$ time periods at an arbitrary point in time $t=x$ as shown in the scheme in the Figure 2.

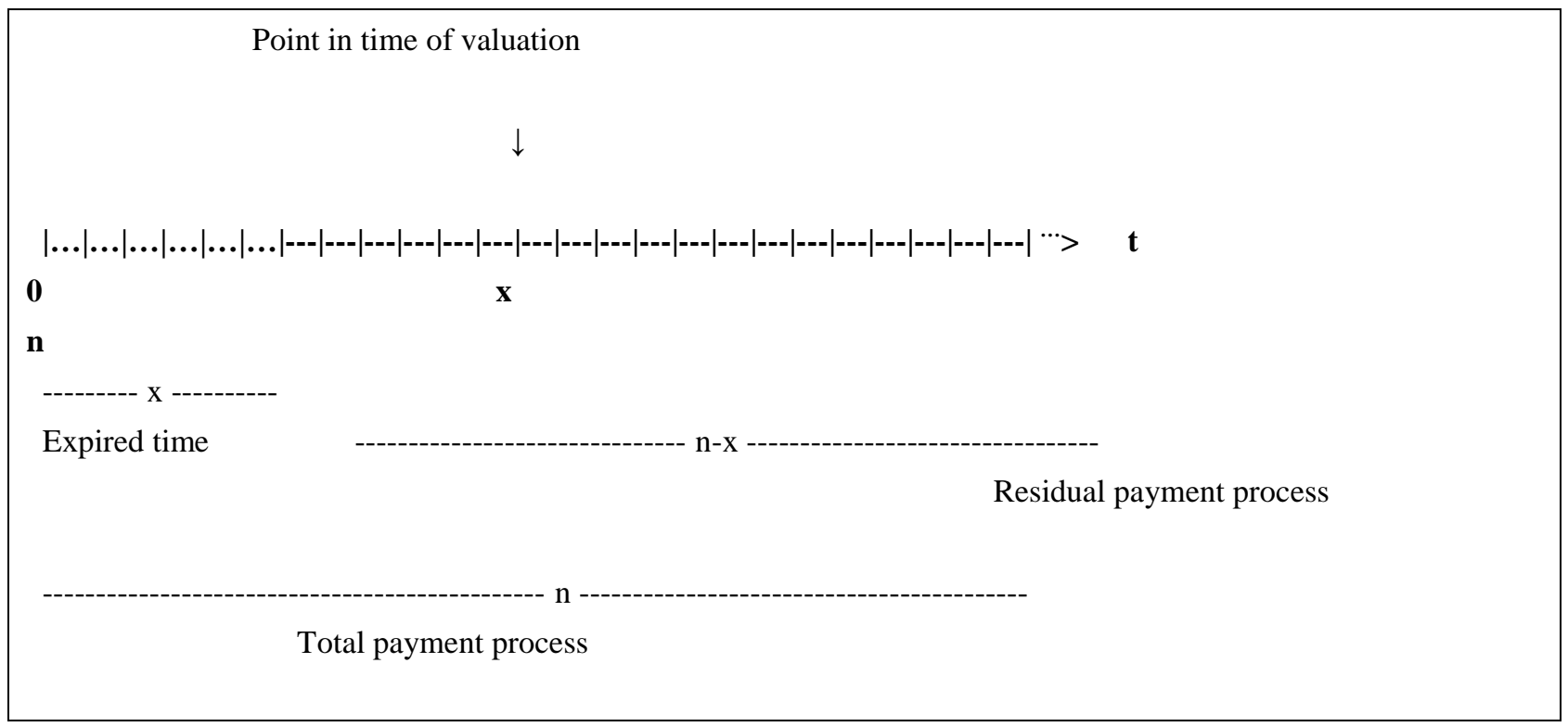

Figure 2. Scheme of a residual payment process after $x$ time periods

Subtracting the GAF $\boldsymbol{a}_{\boldsymbol{k}}(\boldsymbol{0} ; \boldsymbol{x} ; \boldsymbol{q})$ for the expired time $x$ from the GAF $\boldsymbol{a}_{\boldsymbol{k}}(\boldsymbol{0} ; \boldsymbol{n} ; \boldsymbol{q})$ for the total time $n$ and then compounding the difference until the date of valuation after $x$ periods, GAF for this case can be easily derived. The GAF $a_{k}(\boldsymbol{x} ; \boldsymbol{n} ; \boldsymbol{q})$ for the residual time $n-x$ are then generally for $k=0,1,2, \ldots$ defined as

$$
\boldsymbol{a}_{k}(\boldsymbol{x} ; \boldsymbol{n} ; \boldsymbol{q})=q^{x}\left[\boldsymbol{a}_{k}(\mathbf{0} ; \boldsymbol{n} ; \boldsymbol{q})-\boldsymbol{a}_{k}(\mathbf{0} ; \boldsymbol{x} ; \boldsymbol{q})\right]
$$

or including inflation as

$$
\boldsymbol{a}_{k}\left(\boldsymbol{x} ; \boldsymbol{n} ; \boldsymbol{q}^{*}\right)=q^{* x}\left[\boldsymbol{a}_{\boldsymbol{k}}\left(\mathbf{0} ; \boldsymbol{n} ; \boldsymbol{q}^{*}\right)-\boldsymbol{a}_{k}\left(\boldsymbol{0} ; \boldsymbol{x} ; \boldsymbol{q}^{*}\right)\right]
$$


Subject to (7) and (8) and including inflation, the residual payment process and its present value, nominated now as $C F_{x}(t)$ and $P V_{x}$, are:

$$
\begin{gathered}
C F_{x}(t)=\sum_{k=0}^{m} c_{k} \boldsymbol{t}^{k} \boldsymbol{p}^{t-x} \quad(t=x, \ldots, n) \\
m \\
\begin{array}{c}
m V_{x}=\sum c_{k} \boldsymbol{a}_{\boldsymbol{k}}\left(\boldsymbol{x} ; \boldsymbol{n} ; \boldsymbol{q}^{*}\right) . \\
k=0
\end{array}
\end{gathered}
$$

The time parameters $x$ and $n$ must not be integer but decimalized. If the relevant time period is a year, with GAF exact valuation to the day is no problem, for example $x=5.145$ (= 5 years and 53 days) and $n=20.5$ (=20 and a half years).

\subsection{Financial Key Numbers}

GAF enable us for the first time to derive well-known measures like Present Value $P V$, Duration $D$, Convexity $C$ and even Value at Risk $\operatorname{VaR}$ directly from the underlying payment processes $C F(t)$ such as (10) without any calculating, discounting and summation of each payment realisation for time index $t=1, \ldots, n$. The "timeless" computation of these financial key numbers requires only two more GAF of higher degrees $m+1$ and $m+2$ (Wilde, 2005). On behalf of higher generality this is demonstrated for a residual payment process $C F_{x}(t)$ such as (10) valued at an arbitrary point in time $t=x$.

Duration is a measure for the average maturity of a payment process. In the common summation form (see for example Lyuu, 2002) each payment period $t$ is weighted by its present value. Using GAF as defined in (9) or (9a) instead, duration $D_{x}$ can easily be obtained as a general "timeless" closed-form expression (Wilde, 2005)

$$
\begin{gathered}
m \\
D_{x}=\sum c_{k} \boldsymbol{a}_{k+1}(\boldsymbol{x} ; \boldsymbol{n} ; \boldsymbol{q}) / P V_{x}-x[\text { periods }] .
\end{gathered}
$$

Because of the additional multiplication by $t$, the GAF in the numerator are one degree higher $(k+1)$ than in the formula for the according present value in (11).

Convexity is a measure for the change of duration as market yield changes. In the usual summation form (see for example Lyuu, 2002) it includes linear and quadratic terms of $t$. Using GAF of degree $k+1$ and degree $k+2$ in the numerator, we obtain in a similar fashion a general closed-form expression for convexity $C_{x}$ (Wilde, 2005)

$$
\begin{gathered}
C_{x}=1 / q^{2}\left\{\left[\sum c_{k}\left[\boldsymbol{a}_{\boldsymbol{k}+2}(\boldsymbol{x} ; \boldsymbol{n} ; \boldsymbol{q})+(1-2 x) \boldsymbol{a}_{\boldsymbol{k}+\boldsymbol{l}}(\boldsymbol{x} ; \boldsymbol{n} ; \boldsymbol{q})\right] / P V_{x}+\left(x^{2}-x\right)\right\} .\right. \\
k=0
\end{gathered}
$$

In both formulae (12) and (13) GAF $\boldsymbol{a}_{\boldsymbol{k}}(\boldsymbol{x} ; \boldsymbol{n} ; \boldsymbol{q})$ can be substituted by inflation including GAF $\boldsymbol{a}_{\boldsymbol{k}}\left(\boldsymbol{x} ; \boldsymbol{n} ; \boldsymbol{q}^{*}\right)$ if the underlying payment process is exposed to inflation.

With formulae (12) and (13) computation of a common risk measure, the Value at Risk VaR, is now straightforward. $\operatorname{VaR}$ measures the effect of interest rate volatility on the market value. For a given percent confidence level, e.g. 99 percent, $\operatorname{VaR}$ indicates the worst change of $99 \%$ of the market value changes caused by this risk factor, thus excluding only $1 \%$ of extreme cases of even worse value changes. With the Delta-Gamma-Method, assuming that changes of interest rates are normally distributed with a standard deviation or volatility $\sigma$ (Jorion, 2007), VaR is given by

$$
V a R_{x}=P V_{x}+\alpha\left[\left(-1 / q D_{x} P V_{x}(q-1) \sigma\right)^{2}+1 / 2\left(C_{x} P V_{x}(q-1)^{2} \sigma^{2}\right)^{2}\right]^{1 / 2},
$$

where the standard normal deviate $\alpha$ corresponds to the specified confidence level, e.g. $\alpha=2.33$ for 99 percent.

\section{Economical Applications}

Many economical processes, especially financial processes, are exactly determined by time, for instance coupon payments of bonds or amortizations of loans. Realisations of these processes can be calculated exactly for certain points in time. Other processes, as for instance expenses for pensions, taking in account mortality, are statistically 
determined by time (age) dependent probabilities of survivorship. In life-cycle models the predicted payments depend on reasonable assumptions concerning the control parameters.

\subsection{Valuation of Loans}

In practice, there is a large variety of loan (mortgage) types due to different terms of amortization and interest fixing. Well-known and widely spread types are Constant Payment Loans with a constant sum (annuity) of interest and principal (amortization) payments at each period and Constant Amortization Loans with constant amortization payments, but interest payments based on the remaining balance in the beginning of the period (Goddard \& Marcum, 2012). The interest rate may be fixed for the total period of a loan contract or for a part of it only.

In order to demonstrate the application of GAF in general as well as in terms of numbers, we consider a Constant Amortization Loan with a fixed interest rate for the total period of the loan contract. The constant reduction of the loan principal by amortization over the total loan period of $n=20$ years implies interest payments decreasing with time (see Figure 3). At the date of valuation after $x=5$ years there may be only $n-x$ remaining periods, here 15 years. For such a loan with a principal $L=\$ 1,000,000$ and a contracted interest rate $r=3 \%$ the cash flows for principal and interest, stated in the polynomial structure of (7), describe an exact linear residual payment process of maximum degree $m=1$ (Wilde, Oelmann \& Römmich, 2015)

$$
C F_{x}(t)=c_{0} t^{0}+c_{1} t^{1}(t=x, \ldots, n)
$$

with characteristic coefficients $c_{0}=L / n(r n+r+1)=1,000,000 / 20 *(0.03 * 20+0.03+1)=81,500$ and $c_{1}=-L / n r=-1,000,000 / 20 * 0.03=-1,500$.

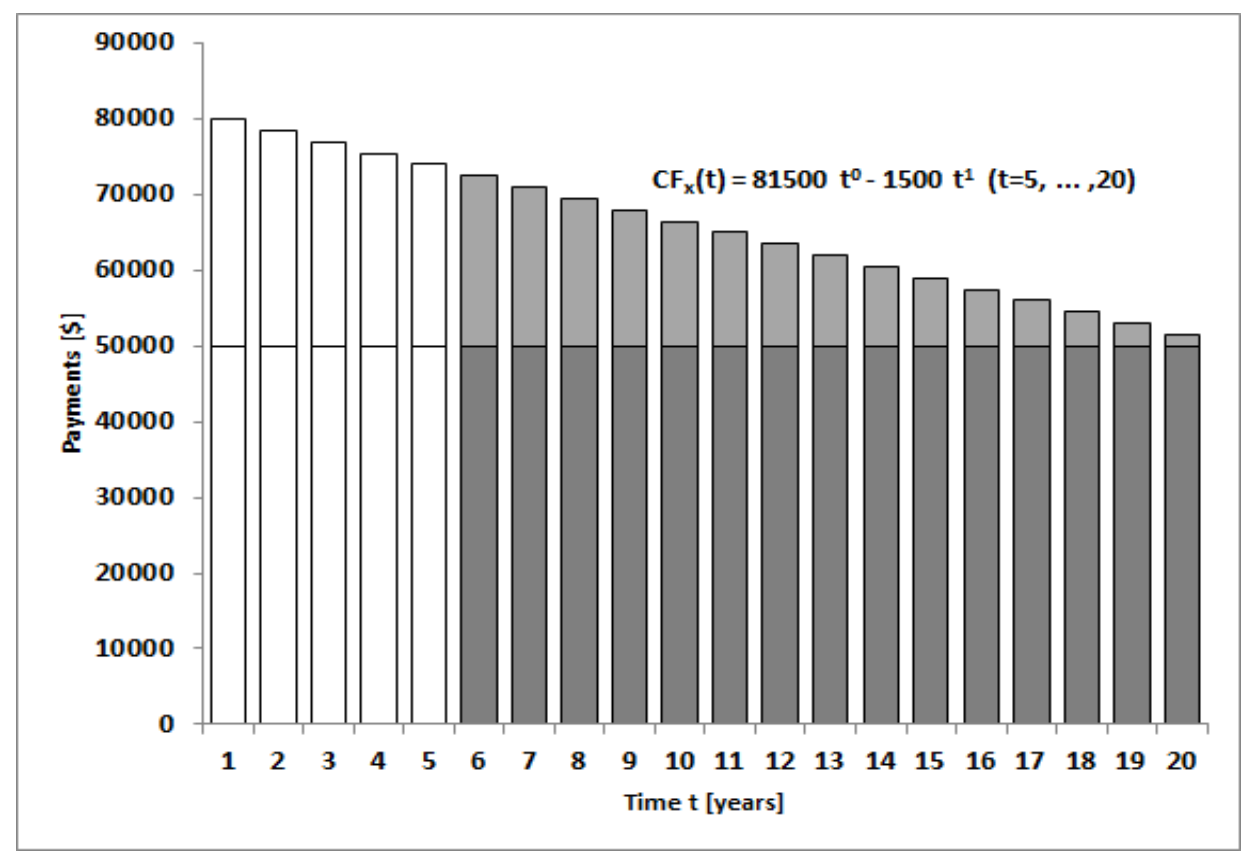

Figure 3. Cash flow process of a Constant Amortization Loan

Applying the GAF-concept with (11), (12) and (13), we obtain more comprehensive formulae for present value or market value, duration and convexity in the case of loans as shown in Figure 4 (Valuation results). After recursive computation of the needed GAF $\boldsymbol{a}_{k}(\mathbf{5 ; 2 0 ; 1 . 0 2}), k=0, \ldots, 3$ for a given market rate of $i=2 \%(q=1,02)$, we obtain all valuation results for the loan including Value at Risk with (14) for a 99 percent confidence level $(\alpha=2.33)$ and for a given interest rate volatility of $\sigma=15 \%$ p.a.. The procedure can be tracked in Figure 4 . With the new powerful tool of GAF, valuation can be done in a few steps in a spread sheet program having implemented User Defined Functions for the GAF. There is no need for classic "time table" based computation anymore. 


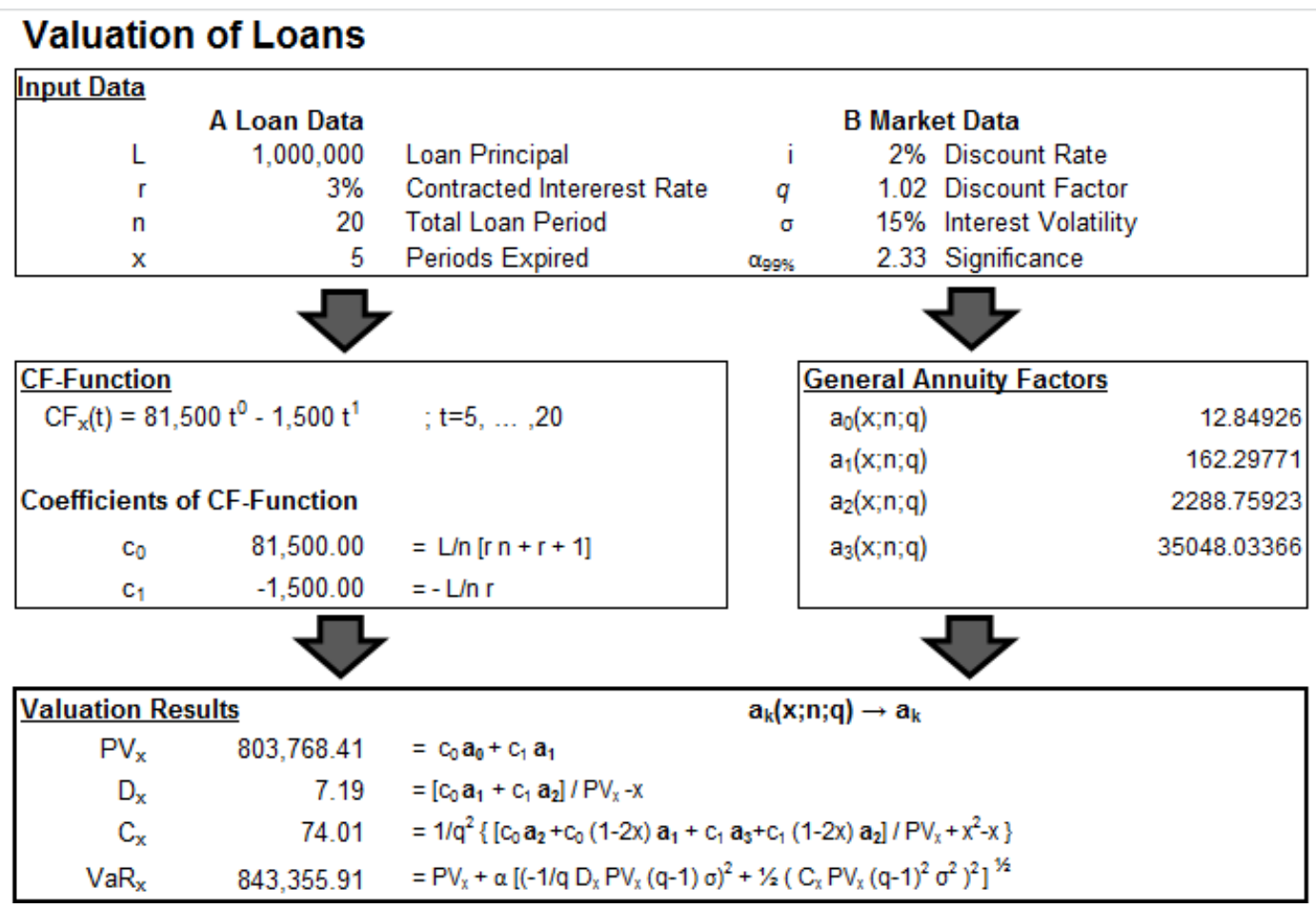

Figure 4. Easy valuation of loans with User Defined GAF-functions

At the date of valuation after 5 years the market value of the loan $(\$ 803,768.41)$ surmounts its residual book value $(\$ 750,000)$ by $\$ 53,768.41$ and could even - due to further decline of the market interest rate in the sight of a year climb up to $\$ 843,355.91,1 \%$ of worse cases excluded. As duration (7.19 years) is also available, as a measure of average maturity of the loan payments, it can be used for discounting by the more exact duration-matched market rate $i_{D}$ from the yield curve (Jorion, 2007 and Wilde, 2015) instead by the given rate of $2 \%$.

For the simpler case of Constant Payment Loans the residual payment function with a maximum degree $m=0$ is defined as

$$
C F_{x}(t)=c_{0} t^{0}(t=x, \ldots, n)
$$

with a coefficient $c_{0}=L / \boldsymbol{a}_{\boldsymbol{0}}(\mathbf{0} ; \boldsymbol{n} ; \mathbf{1}+\boldsymbol{r})$ where $r$ is the contracted interest rate.

Again, using GAF, resulting formulae for present value, duration and convexity are far more compressed:

$$
\begin{gathered}
P V_{x}=c_{0} \boldsymbol{a}_{0}(\boldsymbol{x} ; \boldsymbol{n} ; \boldsymbol{q}), \\
D_{x}=\boldsymbol{a}_{1}(\boldsymbol{x} ; \boldsymbol{n} ; \boldsymbol{q}) / P V_{x}-x \text { and } \\
\left.C_{x}=1 / q^{2}\left[c_{0} \boldsymbol{a}_{2}(\boldsymbol{x} ; \boldsymbol{n} ; \boldsymbol{q})+c_{0}(1-2 x) \boldsymbol{a}_{1}(\boldsymbol{x} ; \boldsymbol{n} ; \boldsymbol{q})\right] / P V_{x}+\left(x^{2}-x\right)\right\} .
\end{gathered}
$$

Because of lower amortizations in the first years we find a higher market value $(\$ 863,672.34)$ and a higher duration (7.63 years) compared with the Constant Amortization Loan considered before.

\subsection{Product Life-Cycle Valuation}

Introducing a new product, a life-cycle valuation gives an insight in the overall profitability of a product dependent on certain control parameters (basically Levitt, 1965). A frequently used product life-cycle model is a time dependent combined quadratic exponential sales function (Isaic -Maniu \& Voda, 2008) with a growth stage at first and then a decline stage as shown in Figure 5. The shape of the life-cycle, especially the expected period of the sales maximum, can be controlled by the parameters $s$ and $m$. Thus for each period $t$ of the life-cycle lasting $n$ periods we can forecast the product sales by

$$
Q(t)=s t^{2} e^{-m t} \quad(t=1, \ldots, n)
$$


where $\mathrm{e}=2,71828 \ldots$ is the Eulerian number, $s$ is a scaling factor and $m$ is determined by the number of periods $t_{\max }$ until the maximum quantity $Q_{\max }$ of product sales $\left(m=2 / t_{\max }\right)$ has been reached.

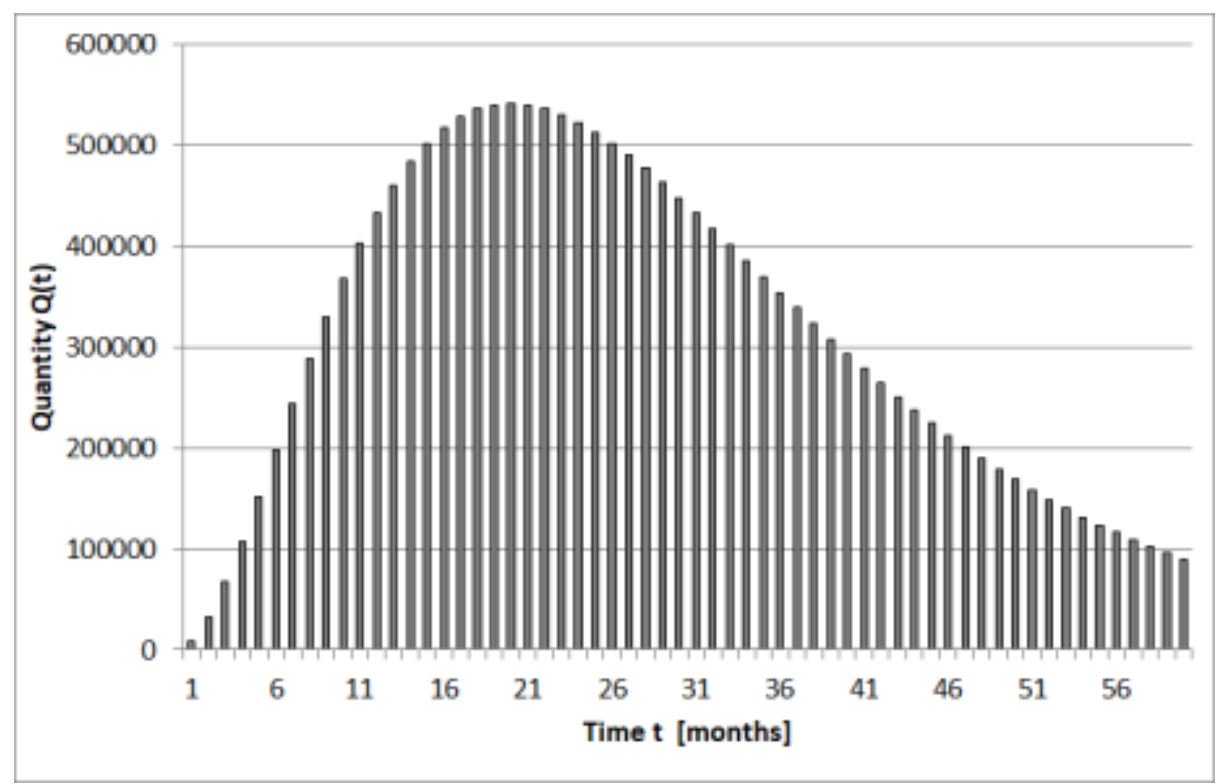

Figure 5. Product life-cycle $Q(t)=10000 t^{2} e^{-0,1 t}(\mathrm{t}=1, \ldots, 60$ months $)$ with $Q_{\max }=541,341$ units at $t_{\max }=20$ months

In the growth stage of the market, higher prices can be realized which is reversed in the decline stage. Assuming a linear dependency of the realizable equilibrium price on sales from (20) we have

$$
P(t)=b+c Q(t)=b+c s t^{2} e^{-m t}
$$

where $b$ is the expected base price and $c$ the price increment per product unit.

The product of (20) and (21) is the time dependent turnover function

$$
T(t)=Q(t) P(t)=s b t^{2} e^{-m t}+s^{2} c t^{4} e^{-2 m t} .
$$

On the other hand, costs shall be described by a linear function of product quantities in each period as

$$
C(t)=f+v Q(t)=f+v s t^{2} e^{-m t}
$$

where $f$ are the fix costs per period and $v$ are the variable costs per product unit. Finally, with (22) and (23) we find the profit or earning function for the entire product life-cycle, stated in the polynomial form of (10), as

$$
E(t)=T(t)-C(t)=-f \boldsymbol{t}^{0}+(b-v) s \boldsymbol{t}^{2} \boldsymbol{e}^{-m} t+c s^{2} \boldsymbol{t}^{4} \boldsymbol{e}^{-2 m t}
$$

With (11) we directly obtain the profit present value of the product life-cycle by simply substituting the time powers for $k=0,2$ and 4 in (20) by the according GAF $\boldsymbol{a}_{k}\left(\boldsymbol{0} ; \boldsymbol{n} ; \boldsymbol{q}^{*}\right)$ with e.g. a modified discounting factor $q^{*}=q / e^{-m}$ for the second term

$$
P V_{E}=-f \boldsymbol{a}_{0}(\boldsymbol{0} ; \boldsymbol{n} ; \boldsymbol{q})+(b-v) s \boldsymbol{a}_{2}\left(\boldsymbol{0} ; \boldsymbol{n} ; \boldsymbol{q} / \boldsymbol{e}^{-m}\right)+c s^{2} \boldsymbol{a}_{\mathbf{4}}\left(\mathbf{0} ; \boldsymbol{n} ; \boldsymbol{q} / \boldsymbol{e}^{-2 m}\right)
$$

With control parameters $s$ and $m$ of the product life-cycle function, $b$ and $c$ of the price function and $f$ and $v$ of the cost function there are several adjusting screws to fit our life cycle model to practical cases. For example for a short living retail product with a horizon of 60 months, expecting a maximum sale of over 500,000 units per month after a third of life time, i.e. 20 months, the according life-cycle function shown in Figure 5 with parameters $s=10,000$ and $m=-0.1$ may be suitable. Furthermore, it is expected to realize a base price of $b=2 \$ /$ unit with a price increment of $c=0.02 \$ / 1000$ units, reflecting the market situation in the growth and the decline stage. The fix costs are estimated as $f=200,000 \$ /$ period and the variable costs as $v=1.8 \$ /$ unit by experience. Inserting these dates in (25) and discounting with a monthly rate of $i=3 \% / 12$ or a monthly discounting factor $q=1.0025$ we immediately calculate a profit present value of the product life-cycle

$P V_{E}=-200,000 \boldsymbol{a}_{0}(\mathbf{0} ; \mathbf{6 0} ; \mathbf{1 . 0 0 2 5})+(2-1.8) * 10,000 \boldsymbol{a}_{2}\left(\mathbf{0} ; \mathbf{6 0} ; \mathbf{1 . 0 0 2 5} / \boldsymbol{e}^{-0.1}\right)+0.02 / 1000 * 10,000^{2} \boldsymbol{a}_{4}\left(\mathbf{0} ; \mathbf{6 0} ; \mathbf{1 . 0 0 2 5} / \boldsymbol{e}^{-0.2}\right)$ 


\section{$=\underline{\$ 6,398,248}$}

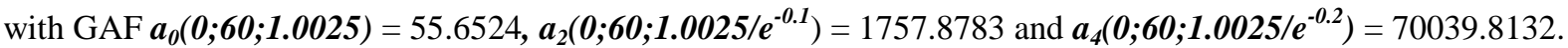

Considering a short product life-cycle of only 5 years, calculation of $\mathrm{VaR}$ in respect to changes of the market rate $i$ is secondary in comparison to other parameters. Rather, a sensitivity analysis in respect to high risk parameters is favourable: for example varying variable costs $v=1.8+/-10 \%$ results in a much stronger variation of the present value $P V_{E}=\$ 6,398,248-/+49.5 \%$.

Apparently, the above model could be used to describe a much more differentiated Dividend Growth Model introducing a retention rate into (24) and (25) to calculate time-dependent dividend payments. More realistic than in the models discussed in the recent paper of Holland (2018), it offers both growing and declining growth rates dependent on the stage in the life cycle of an enterprise.

\subsection{Valuation of Pension Obligations}

Like loans also pension obligations usually account for an important portion of the balance sheet. The application of GAF will be shown for the valuation of all future payments to current retirees of a certain age $x$ taking the empirical mortality into account. Thereto and also for the valuation of pension obligations of active workers, we refer to AUTHOR (2016).

National probabilities of survivorship are published in so called mortality tables for any age up to at least 100 . Looking at the male population in Germany (Statistisches Bundesamt, 2014), the tabulated absolute probabilities of survivorship $l_{t}$ can be approximated by a unique age dependent function $l(t)$ for the relevant range of pension ages between 65 and 100. As shown in Figure 6 good approximations of empirical probabilities of survivorship using the interpolation approach of Neville-Atkins (Phillips \& Taylor, 1996) can be achieved by an age dependent survivorship function $l(t)$, e.g. by a polynomial function such as (7) of degree $m=4$

$$
l(t)=c_{0} t^{0}+c_{1} t^{1}+c_{2} t^{2}+c_{3} t^{3}+c_{4} t^{4}(t=65, \ldots, 100) .
$$

With the probabilistic survivorship function $l(t)$ we now can easily define any residual pension payment process $C F_{x}(t)$, e.g. for an $x=70.5$ year old retiree with a current pension of $P=\$ 3,000$ per month $(\$ 36,000$ per year) taking into account an expected yearly average pension increase of $p \%=1.5 \%(p=1.015)$. As $l(t)$ stands for survivorship probabilities of new born persons, but the retiree has already reached age $x$, they have to be divided by $l(x)$ using (26). Thus on a yearly base the residual pension payment process is

$$
C F_{x}(t)=P / l(x) l(t) p^{t-x}(t=x, \ldots, n)
$$

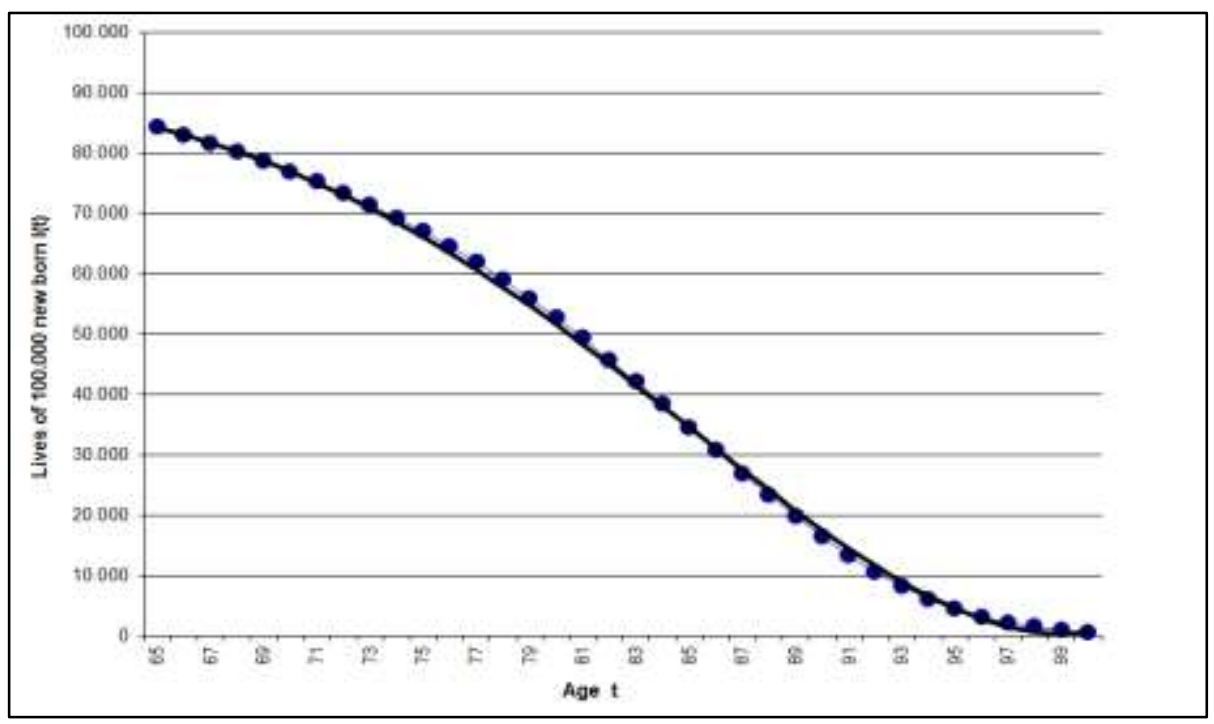

Figure 6. Functional approximation $l(t)$ of absolute probabilities of survivorship $l_{t}$ (dotted line)

for German men between age 65 and 100 (lives out of 100.000 born male persons)

or substituting $l(t)$ by the polynomial structure of (26) with a growth factor $p$

$$
C F_{x}(t)=P / l(x) \sum^{4} c_{k} \boldsymbol{t}^{k} \boldsymbol{p}^{t-x}(t=x, \ldots, n) .
$$


The estimated coefficients $c_{k}$ based on the German mortality table are documented in Figure 7. After recursive

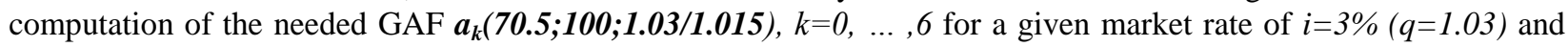
applying formulae (11), (12), (13) and (14) for present value, duration, convexity and value at risk in the case of the pension expenses, it is possible to obtain all the valuation results for an $x=70.5$ year old retiree. Again it is the same procedure as with loans. The single steps can be tracked in detail in Figure 7.

\section{Valuation of Pension Obligations}

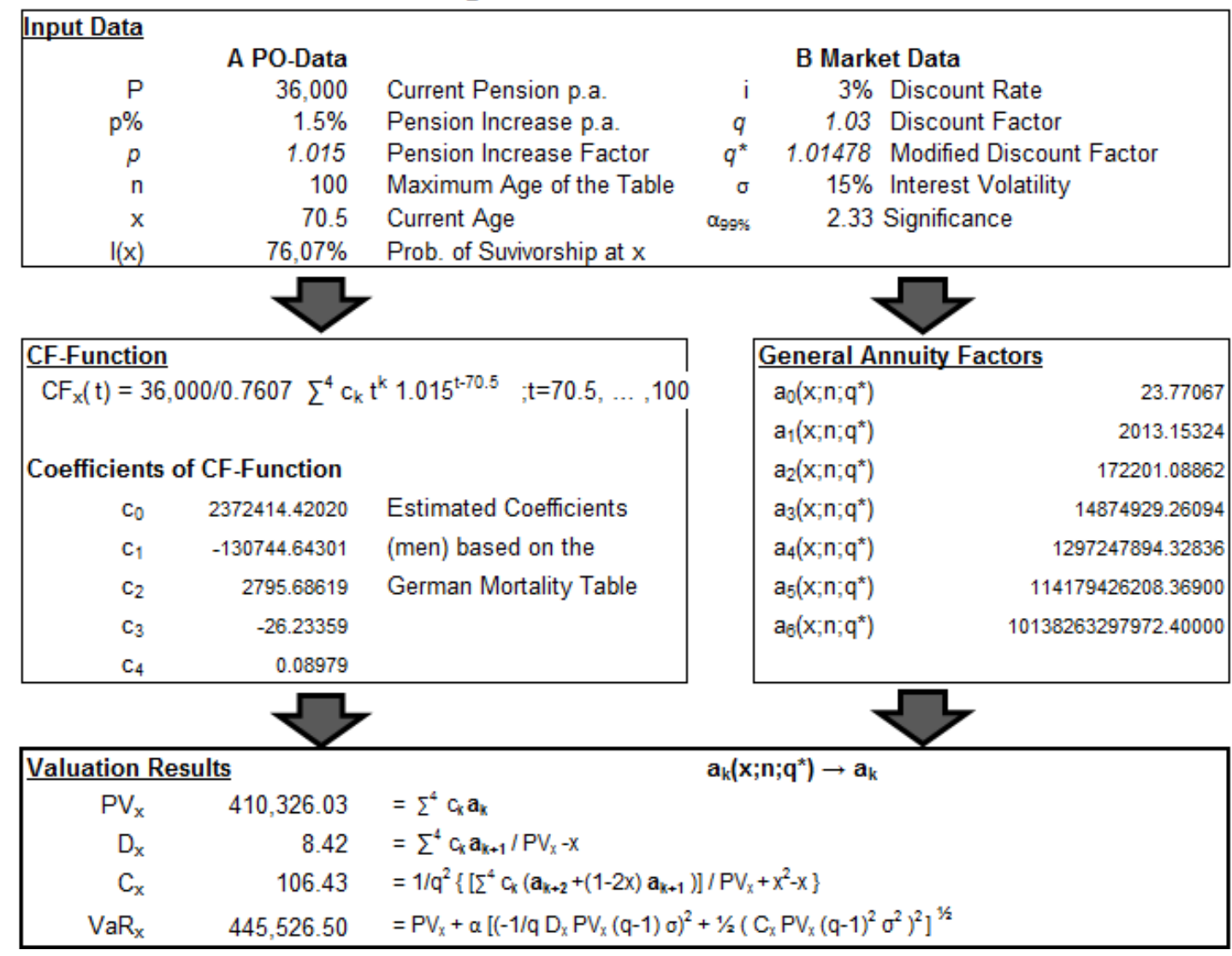

Figure 7. Easy valuation of pension obligations with User Defined GAF-functions

Valuation of the residual future pension expenses in the case of an $x=70.5$ year old male retiree results in a present value of $\$ 410,326.03$. Due to further decline of the market rate, the value at risk could climb up to $\$ 445,526.50$ within one year. The duration of $D=8.42$ years indicates the average maturity of the future pension expenses for men having reached an age of 70.5 years. Again, discounting by a duration-matched market rate $i_{D}$ could improve the valuation results.

Assuming a certain development of the market interest rate $i_{t}$ for the next three years (e.g. 3.3\%, 3.6\% and 4\%, thus $\left.q_{t}=1.033 / 1.036 / 1.04\right)$, one can immediately forecast the development of the present values with the according GAF $\boldsymbol{a}_{\boldsymbol{k}}\left(\mathbf{7 0 . 5 + t} ; \mathbf{1 0 0} ; \boldsymbol{q}_{t} / \mathbf{1 . 0 1 5}\right), t=1,2,3$. Using the scheme of Figure 7 one finds a strongly declining development of present values $(\$ 387.931 / \$ 367.018 / \$ 345.009)$ due to growing age but also due to rising market interest rates.

Regarding a normally monthly payment of pensions we obtain a monthly cash flow function by a slight modification of the yearly cash flow function (27a)

$$
{ }_{12} C F_{x}(t)=P / 12 / l(x) \sum^{4} c_{k}(\boldsymbol{t} / \mathbf{1 2}){ }^{\boldsymbol{k}} \boldsymbol{p}^{(t-x) / 12}(t=12 x, \ldots, 12 n) .
$$

Using the above input data, we then obtain an according present value ${ }_{12} P V_{x}=\$ 426,611.97$ resulting in a higher value because of the earlier monthly paying. Thus the according duration ${ }_{12} D_{x}=8.1$ years is shorter. 


\section{Conclusion}

It has been proved that Halley's more than 250-year-old closed-form formula for valuation of constant payments can be generalized to a wide variety of time-dependent cash flow processes. Three numerical examples concerning

- deterministic linear and constant loan payments

- predicted nonlinear payments during a product life-cycle and

- stochastic cash flows caused by pension obligations following an age-dependent probability function of fourth time degree

demonstrate that with General Annuity Factors (GAF) a large spectrum of valuation and risk measurement tasks can now be done by closed-form expressions.

Crucial for practical application: GAF can be computed recursively starting from the well-known formula of Halley's Annuity Factor and can be implemented as User Defined Functions in a spreadsheet program. All the calculations are easy and can be done in only one cell of a spreadsheet program. This makes the usual "time tables" with interim discounting results superfluous. Instead there is an easy to handle, universally usable calculation scheme: first derive the coefficients of the underlying cash flow function from input data, second combine the coefficients with the according GAF to immediately obtain all the needed valuation results.

Compression of a large number of future payments into a unique cash flow function by modelling the expected cash flow either exactly or approximately saves a huge amount of computation. In addition, such a cash flow function makes it possible to calculate the present value and further financial key numbers as duration or value at risk in a very efficient way - simply by substituting the time terms of the cash flow function by the according GAF. Thus the formulae for the financial key numbers preserve the structure of the original cash flow function.

Altogether easy application and computation of GAF provide a direct access to value and risk measurement even of complex payment processes also for smaller enterprises or public services. With this new tool, for those users it is possible to control their liability status derived from loans or pension obligations relative to the market situation without external support. GAF are already in practical use in a medium sized enterprise for valuation of long-living wastewater assets under the special conditions of public fees and for valuation of investments in renewable energy projects (Wilde, Oelmann \& Römmich, 2015). Furthermore, GAF are the centrepiece of an Asset Liability Management Model of a pension fund with a prediction horizon until 2040 (Wilde, 2016). Further applications can be assumed in the finance, insurance and actuarial area, but GAF are also appropriate for life -cycle studies and even for exotic tasks like forest valuation.

Using GAF, the comparison of different valuation scenarios by variation of parameters or far-reaching forecasts can be done notably more efficient now. Thus the expanded application potential in connection with computational efficiency may revitalize Halley's basic concept of Annuity Factor in a new, more general context. There is no reason anymore to restrict his concept to constant payments only. Future research should go forward in two directions: on the one hand extending the GAF-concept in a theoretical way to cover further features of payment processes in addition to those shown in this paper and, on the other hand, defining further time dependent payment processes relevant for economical applications not mentioned yet.

\section{References}

Goddard, G.J., Marcum, B. (2012). Real Estate Investment. A Value Based Approach. New York, NY: Springer. https://doi.org/10.1007/978-3-642-23527-6

Gordon, M. (1962). The Investment, Financing and Valuation of the Corporation. Homewood, Ill.: RD. Irwin.

Halley, E. (1761). Of Compound Interest. Henry Sherwin, Sherwin's Mathematical Tables, published posthumously after Halley's death in 1742. London, England: W. and J. Mount, T. Page and Son.

Holland, L. (2018). A Flexible Valuation Model Incorporating Growth Rates. Accounting and Finance Research, 7(1), 116-128. https://doi.org/10.5430/afr.v7n1p116

Isaic-Maniu, A., Voda, V. (2008). On a Model Regarding the Product Life Cycle. Management \& Marketing, 3(3), 87-96.

Jorion, P. (2007). Value at Risk: The New Benchmark for Managing Financial Risk (3nd ed.). New York, NY: McGraw-Hill.

Levitt, T. (1965). Exploit the Product Life Cycle. Harvard Business Review, 43(11), 81-94. 
Lyuu, Y. (2002). Financial Engineering and Computation: Principles, Mathematics, Algorithms. Cambridge, England: University Press.

Phillips, G., Taylor, P. J. (1996). Theory and Applications of Numerical Analysis (2 ${ }^{\text {nd }}$ ed.). London, England: Elsevier Academic Press.

Rubinstein, M. (2003). Great Moments in Financial Economics: I. Present Value. Journal of Investment Management, 1.Q. 2003, 1-17.

Statistisches Bundesamt (2014). Aktuelle Sterbetafel für Deutschland 2010/2012. Retrieved from https://www.destatis.de/DE/Publikationen/Thematisch/Bevoelkerung/Bevoelkerungsbewegung/SterbetafelnAllg emeinErlaeuterung5126205129004.pdf?__blob=publicationFile (Translation of title: Actual Mortality Table for Germany 2010/2012)

Wilde, J. (2005). Ein neues allgemeines Verfahren zur direkten Barwertermittlung für diskrete zeitabhängige Zahlungsprozesse. Vortrag vor dem Ökonomischen Forschungsseminar an der Westfälischen Wilhelm Universität Münster am 21.12.2005, 1-21. (Translation of title: A New General Approach of Computing Present Values for Discrete Time Dependent Payment Processes)

Wilde, J. (2016). Der Allgemeine Rentenbarwertfaktor als effizientes Controlling-Instrument für Pensions-verpflichtungen - von besonderer Bedeutung in Zeiten der Zinsschmelze. CONTROLLING Zeitschrift für erfolgsorientierte Unternehmenssteuerung, 28(11), 676-685. (Translation of title: The General Annuity Factor as an Efficient Controlling Instrument for Pension Obligations - of Especial Importance in Times of an Interest Melting). https://doi.org/10.15358/0935-0381-2016-11- 676

Wilde, J. (2018). Vorausschauendes Asset Controlling mittels Allgemeiner Rentenbarwertfaktoren - dargestellt am Beispiel der Wasserwirtschaft. CONTROLLING - Zeitschrift für erfolgsorientierte Unter- nehmenssteuerung, 30(1), 11-20. https://doi.org/10.15358/0935-0381-2018-1-11 (Translation of title: Farsighted Asset Controlling with General Annuity Factors - Demonstrated for the Water Economy). https://doi.org/10.15358/0935-0381-2018-1-11

Wilde, J., Oelmann, M. \& Römmich, M. (2015). Der Allgemeine Rentenbarwertfaktor als Instrument der Bewertung von Infrastrukturnetzen - Das Beispiel der Übernahme eines kommunalen Abwassernetzes. CONTROLLING Zeitschrift für erfolgsorientierte Unternehmenssteuerung, 27(7), 396-402. (Translation of title: The General Annuity Factor as an Instrument for Valuation of Infrastructure Networks - Demonstrated for a Takeover of Municipal Waste Water Channels). https://doi.org/10.15358/0935-0381-2015-7-396 


\section{Appendix}

Proof of the General Annuity Factor (AUTHOR, 2005):

Let again for simplicity $q=1+i$. Then the $n$-sum of discounted $m$-th time powers $\Sigma t^{m} q^{-t}$ can be written explicitly

$$
\begin{aligned}
& n \\
& \boldsymbol{a}_{\boldsymbol{m}}(\boldsymbol{0} ; \boldsymbol{n} ; \boldsymbol{q})=\Sigma t^{m} q^{-t}=1 q^{-1}+2^{m} q^{-2}+\ldots+t^{m} q^{-t}+\ldots+(n-1)^{m} q^{-n}+n^{m} q^{-n} . \\
& t=1
\end{aligned}
$$

Subtracting this sum from its $q$-fold we have

$$
\begin{array}{cc}
N & n-1 \\
(q-1) & \sum t^{m} q^{-t}=1+\sum\left[(t+1)^{m}-t^{m}\right] q^{-t}-n^{m} q^{-n} .
\end{array}
$$

Completing the $(n-1)$-sum by an additional term $\left[(n+1)^{m}-n^{m}\right] q^{-n}$ which has to be subtracted at the same time we obtain

$$
\begin{array}{cc}
n & n \\
(q-1) \sum_{t=1}^{m} q^{-t}=1-(n+1)^{m} q^{-n}+\sum\left[(t+1)^{m}-t^{m}\right] q^{-t} . \\
t=1
\end{array}
$$

Using the general binomial rule for the binomial $(t+1)^{m}$ and rearranging summation we have

$$
\begin{aligned}
& n \quad n \\
& (q-1) \Sigma t^{m} q^{-t}=1-(n+1)^{m} q^{-n}+\Sigma\left[\left(t^{m}+\left({ }^{m}{ }_{1}\right) t^{m-1}+\ldots+\left({ }^{m}{ }_{m-1}\right) t^{1}+1\right)-t^{m}\right] q^{-t} \\
& t=1 \quad t=1 \\
& m-1 \quad n \\
& =1-(n+1)^{m} q^{-n}+\Sigma\left({ }^{m}{ }_{k}\right) \Sigma \boldsymbol{t}^{k} \boldsymbol{q}^{-t} \text {. } \\
& k=0 \quad \boldsymbol{t}=\mathbf{1}
\end{aligned}
$$

Dividing by $(q-1)$ und substituting the $n$-sums $\Sigma t^{k} q^{-t}$ by the corresponding GAF $\boldsymbol{a}_{k}(\boldsymbol{0} ; \boldsymbol{n} ; \boldsymbol{q})$ of lower degrees $k=0, \ldots$, $m-1$ the proposed closed-form of (5) for the GAF $\boldsymbol{a}_{\boldsymbol{m}}(\mathbf{0} ; \boldsymbol{n} ; \boldsymbol{q})$ of any degree $m$ is obtained

$$
\begin{gathered}
m-1 \\
\left.\boldsymbol{a}_{\boldsymbol{m}}(\mathbf{0} ; \boldsymbol{n} ; \boldsymbol{q})=\left[1-(n+1)^{m} q^{-n}+\sum_{k=0}^{m}{ }_{k}\right) \boldsymbol{a}_{k}(\mathbf{0} ; \boldsymbol{n} ; \boldsymbol{q})\right] /(q-1) \text { with } q \neq 1 \\
k=0
\end{gathered}
$$

